\title{
Assessment of Attitude of Primary Care Medical Staff Toward Patient Safety Culture in Primary Health-care Centers - Al-Ahsa, Saudi Arabia
}

\author{
Mohammed M AIMaani' \\ Khaled F Salama (iD ${ }^{2}$ \\ 'King Abdulaziz-National Guard Hospital \\ Al-Ahsa, Dammam, Saudi Arabia; \\ ${ }^{2}$ Department of Environmental Health, \\ College of Public Health, Imam \\ Abdulrahman Bin Faisal University, \\ Dammam, Saudi Arabia
}

Introduction: An effective leadership is critical to the development of a safety culture within an organization. Patient safety in primary health care is an emerging field of research of increasing importance.

Objective: This study has been conducted to explore the safety culture attitude toward patient safety to improve the quality and patient safety in primary health-care centers.

Methods: A cross-sectional survey involving 288 medical staff in primary health-care centers in Al-Ahsa was conducted using an Arabic translated safety attitude questionnaire to assess the safety attitudes among health care center staff toward patient safety culture.

Results: This study showed that the attitude of medical staff in primary health-care centers is somewhat positive toward patient safety culture where the average of job satisfaction score in the current study was higher at $80 \%$ and the overall score for safety climate was $68 \%$. The overall score for safety attitudes was highest in Al-Ayoun Health Center $(79 \%)$ and lowest in Al Faisaliah Health Center (58\%). The score of teamwork and stress recognition was high and statistically significant $(p<0.05)$ among females. However, staff perception toward management was significantly higher $(p<0.05)$ among males. Staff perception toward management was significantly low $(p<0.05)$ among clinicians. The overall score for safety attitudes was remarkably high $(p<0.05)$ among those with less than 10 years' experience, the overall safety culture score was significantly high $(p<0.05)$ among administrative staff and all correlations were significant $(p<0.01)$ except for recognition of stress with teamwork, job satisfaction, management perception, and safety climate. In addition, there were different attitudes toward patient safety culture between gender and physician vs non-physician and management staff vs nonmanagement staff.

Conclusion: The findings suggested that certain improvements are needed, especially in the field of communication and stress recognition with regard to patient safety culture.

Keywords: primary health-care center, safety attitude, patient safety, safety climate, work condition

\section{Introduction}

In the current health-care setting, systems are increasingly becoming complex as caregivers are compelled to work in a fast-moving and pressurized environment thereby elevating the possibilities of clinical errors and harm to patients. ${ }^{1}$

As a way of combating these rapid incidences, health-care institutions are striving to improve their performance as well as recognize the significance of
Correspondence: Khaled F Salama Department of Environmental Health, College of Public Health, Imam Abdulrahman Bin Faisal University, PO Box 1982, Dammam, 3I44I, Saudi Arabia Email ksalama@iau.edu.sa 
developing a safety culture for enhancing the behavior and attitude of caregivers toward patients. ${ }^{2}$

The safety attitude is also explained as the freedom from any kind of injury that is caused by negligence in medical care. Safety attitude helps in the reduction of unnecessary issues connected to health care in a smallest possible way. It is also referred to as a safety culture or safety climate ensuring the constant concerns of nurses, health-care workers, and professionals as they are the ones who play an important role in improving and promoting a better and safe environment for staff as well as patients. ${ }^{1-3}$

Patient safety is defined as the prevention and avoidance of adverse events or patients' injuries occurring because of the procedures of health-care delivery. ${ }^{3}$ Healthcare providers working in the primary health-care centers must be empowered with enough background information regarding patient safety to minimize the adverse event, especially where the caregivers are in frontline contact with patients. ${ }^{4}$

Safety culture is an integral part of health-care organizations whereby the conceptualization of shared believes, attitudes, values, norms and behaviors are used to gauge a caregiver's performance toward achieving patient safety. ${ }^{5}$ Majority of the community and population healthcare requirements and needs are being provided at the primary health-care centers, however, the theme of patient's safety culture becomes overshadowed and poorly visualized. ${ }^{6}$

The safety attitude questionnaire (SAQ) was designed to fulfil the assessment of patient safety culture. The framework was developed by the University of Texas Center of Excellence for Patient Safety Research and Practice $^{7,8}$ where the main part of it involves six main factors including, perception of management, stress recognition, teamwork climate, communication, safety climate, working conditions and satisfaction. ${ }^{9}$ SAQ helps in identifying the major expected weakness in the settings of clinics and motivates the reductions of medical errors while suggesting possible interventions for providing quality care. ${ }^{10}$

Najjar et $\mathrm{al}^{11}$ explored the relationship between patient safety attitude and adverse events, they explained that a hospital with a positive safety culture had fewer adverse events. Inconsistent with this finding Sorra et $\mathrm{al}^{12}$ studied the relationship between staff attitude and patient assessment. Moreover, a systematic review performed to explore this association found evidence of association between the patient safety culture and patient outcome existed in the hospital and nursing units. ${ }^{13}$

Primary health care is an essential component of the health-care system, where patient harm and adverse events may occur at any point of care during the treatment process. Assessment of the primary health-care staff toward patient safety attitude is a preliminary step to identify the weakness areas related to patent quality and safety.

This study has been conducted to explore the culture of safety attitudes toward patient safety as it is considered an essential step to improve the quality of patient safety in primary health-care centers. Since, the majority of healthcare provision takes place in primary health care. However, most of the safety attitude studies were carried out in a hospital setting.

\section{Methods}

\section{Study Area}

Primary health-care center (PHC) services in Al Ahsa includes important rehabilitative, curative, preventive, and promotional services, immunization, child health, chronic disease management such as diabetes and hypertension, dental oral health, crucial laboratory investigation services, provision of essential medication, environmental health, disease control, and health education. Moreover, a medical imaging service (X-ray) is available in a limited number of PHCs in the region where the average annual number of visits was 2.6 for every single person of the $\mathrm{Al}$ Ahsa population.

Primary health-care centers in Al Ahsa are distributed among the region in three sectors namely, Al Hofuf sector $(\mathrm{n}=22)$, Al Mubarraz sector $(\mathrm{n}=22)$, and Al Omran sector $(n=23)$ with a total of 67 PHCCs.

Consequently, the total workforce in PHCs was 1659 distributed between physicians, nurses, pharmacists, and allied health personnel employees male and femaleSaudi ( $\mathrm{n}=1440)$ and non-Saudi $(\mathrm{n}=219)$.

\section{Study Design}

This study is based upon the cross-sectional survey that was done in the primary health-care center of Al-Ahsa, Saudi Arabia from February 2020 to May 2020 (approximately four months). The dependent variable of the study is the attitude of primary care medical staff toward patient safety culture in PHCs. However, the independent variable 
includes sociodemographic characteristics, especially participant's gender, years of experience, job title, and position.

\section{Source and Study Population}

The study included the participants from physicians, medical managers, nurses, and other staff in PHC, in Al-Hasa, Saudi Arabia. The inclusion criteria comprises medical workers and staff members employed in the PHC, in AlHasa, Saudi Arabia. While, the new medical and nursing staff working for less than one year and trainees of medical and nursing staff were excluded from the study.

\section{The Sample Sizes}

The sample size for this research is measured by the help of the Raosoft ${ }^{\circledR}$ software program. In addition, for the calculation of the sample, the information considered includes the total number of the workforce in primary health care centers, Al-Ahsa as 1659 , with a $5 \%$ error margin and 95\% confidence interval. Furthermore, this provided the estimation of the sample to be 313. In addition, $10 \%$ extra was added to cover the incomplete answers, resulting in a final sample of 344 employees.

\section{Eligibility Criteria}

The inclusion criteria include the medical workers and staff members employed in the PHC, in Al-Hasa, Saudi Arabia. While the new medical and nursing staff working for less than one year and trainees of medical and nursing staff were excluded from the study.

\section{Collection Methods}

\section{Instruments}

The SAQ tool was selected for the evaluation of safety attitude due to its ease of use and it was rigorously validated, as well as a common tool for collecting data regarding health care safety climate and attitude. It has been widely used in different countries including Saudi Arabia, and has been translated into seven different languages including Arabic. A translated Arabic version was used in this study and prior to administration of the questionnaire, permission was obtained from Dr Ayman Elsous, Israa University Gaza. ${ }^{14,15}$

\section{Questionnaire Data}

The SAQ measures patient safety culture along six subscales: teamwork climate, six items (items 1 to 6), safety climate, seven items (items 7 to 13): job satisfaction, five items (items 15 to 19): stress recognition, four items (items 20 to 23): perceptions of management, five items (items 24 to 28), and working conditions, four items (items 29 to 32), plus employee's perceptions of the quality of their work environment.

The internal consistency was represented by Cronbach's $\alpha$, cutoff $=0.70$ and it exceeded the set cutoff for all subscales ranging from 0.73 to 0.85 , therefore, the overall Cronbach's $\alpha$ was 0.86 , which indicates that each scale demonstrated a good and comparatively high level of reliability.

\section{Ethical Consideration}

This study was approved by Imam Abdulrahman Bin Faisal University research committee with approval reference number IRB-PGS-2020-03-056. Appendix A is a copy of IRB approval. Permission was obtained from PHC managers to participate in the study after giving full information about the aim and purpose of the study. The questionnaire was explained, and verbal consent was obtained from the participants. Appendix B.

\section{Data Analysis}

Data were recorded, tabled, and analyzed by IBM SPSS software version 25. Respondent's characteristics were described by using percentages. To compare the means between two groups a two-sample $t$-test was used. Oneway ANOVA was used to compare the means between several groups.

\section{Results}

The demographic characteristics of the study participants $(\mathrm{n}=288)$ are presented in Table 1. Female participants were comparatively more than male $(\mathrm{n}=175,60.8 \%$ and 113 , $39.2 \%)$. Most of participants were nurses (35.4\%) followed by technologists/technicians (21.5\%), physicians (18.8\%), pharmacists/pharmacy technicians (12.5\%) and others. (11.8\%). Participants aged less than 30 years were $27.8 \%$, from 30 to 40 years were $45.5 \%$, and more than 40 years were $26.7 \%$. Participant's working in the center for less than three years were $13.2 \%$, three to ten years were $58.3 \%$ and more than 10 years were $28.5 \%$. The majority of participants were diploma holders $(70.1 \%)$, then bachelor holders (27.1\%), and board-certified (2.8\%). The majority of the participants were Saudi (90.6\%).

Perception of management had the highest Cronbach's $\alpha$-value and work condition had the lowest value. The closer Cronbach's alpha coefficient is to 1.0, the greater the internal consistency of the items in the instrument or 
Table I Demographics Characteristic for Study Participants in PHCs

\begin{tabular}{|c|c|c|}
\hline & Frequency & Percent \\
\hline \multicolumn{3}{|l|}{ Gender } \\
\hline Female & 175 & 60.8 \\
\hline Male & 113 & 39.2 \\
\hline \multicolumn{3}{|l|}{ Job category } \\
\hline Nurse & 102 & 35.4 \\
\hline Technologist/technician & 62 & 21.5 \\
\hline Physician & 54 & 18.8 \\
\hline Pharmacist/pharmacy tech. & 36 & 12.5 \\
\hline Other & 34 & 11.8 \\
\hline \multicolumn{3}{|l|}{ Years in the center } \\
\hline Less than 3 years & 38 & 13.2 \\
\hline $3-10$ years & 168 & 58.3 \\
\hline More than 10 years & 82 & 28.5 \\
\hline \multicolumn{3}{|l|}{ Job title } \\
\hline Nurse in charge & 9 & 3.1 \\
\hline Manager & 7 & 2.4 \\
\hline Nonsupervisory & 272 & 94 \\
\hline \multicolumn{3}{|l|}{ Age } \\
\hline Less than 30 & 80 & 27.8 \\
\hline 30 to 40 years & $|3|$ & 45.5 \\
\hline More than 40 years & 77 & 26.7 \\
\hline \multicolumn{3}{|l|}{ Education level } \\
\hline Diploma & 202 & 70.1 \\
\hline Bachelor & 78 & 27.1 \\
\hline Board & 8 & 2.8 \\
\hline \multicolumn{3}{|l|}{ Nationality } \\
\hline Saudi & 261 & 90.6 \\
\hline Non-Saudi & 27 & 9.4 \\
\hline
\end{tabular}

Table 2 Internal Consistency of the Scale

\begin{tabular}{|l|c|c|}
\hline Subscale & Cronbach's $\alpha$ & Item Numbers \\
\hline Teamwork & 0.75 & $1-6$ \\
Safety climate & 0.76 & $7-13$ \\
Job satisfaction & 0.83 & $15-19$ \\
Stress recognition & 0.77 & $20-23$ \\
Perception of management & 0.85 & $24-28$ \\
Work condition & 0.73 & $29-32$ \\
Total & 0.86 & All items \\
\hline
\end{tabular}

the scale. Therefore, our findings indicate each scale demonstrated a good and a comparatively high level of reliability such that no sub-scales could be considered to be poorly constructed as shown in Table 2 .

Scale-to-scale correlations were studied by the degree of linear association between pairs of two scales: Pearson's correlation coefficients are shown in Table 3 . The correlation ranged from 0.069 to 0.788 . All the correlations were significant $(p<0.01)$ except stress recognition with teamwork, job satisfaction, perception of management, and safety climate. Moreover, stress recognition was least positively correlated with subscales with teamwork, job satisfaction, perception of management, and safety climate. The total score for each subscale was more positively correlated with perception of management, job satisfaction, and safety climate and work condition 0.739 to 0.788 . However, the least positive correlation of total score was with stress recognition and teamwork ranging from 0.428 to 0.598 .

The minimum and maximum score in each subscale along with mean SD (standard deviation) and score on a 100-point scale are shown in Table 4. Job satisfaction had the highest mean among all the subscales ie 4.20 (with $100 \mathrm{Pt}$ scale of 80 ) followed by teamwork (4.11 with $100 \mathrm{Pt}$

Table 3 Validity of the Scale Using Pearson's Correlation Coefficients

\begin{tabular}{|c|c|c|c|c|c|c|c|}
\hline & Teamwork & $\begin{array}{l}\text { Job } \\
\text { Satisfaction }\end{array}$ & $\begin{array}{l}\text { Stress } \\
\text { Recognition }\end{array}$ & $\begin{array}{l}\text { Perception of } \\
\text { Management }\end{array}$ & $\begin{array}{l}\text { Work } \\
\text { Condition }\end{array}$ & $\begin{array}{l}\text { Safety } \\
\text { Climate }\end{array}$ & $\begin{array}{l}\text { Total } \\
\text { Score }\end{array}$ \\
\hline Teamwork & I & & & & & & \\
\hline Job satisfaction mean & $0.409 *$ & I & & & & & \\
\hline Stress recognition & 0.097 & 0.069 & I & & & & \\
\hline $\begin{array}{l}\text { Perception of } \\
\text { management }\end{array}$ & $0.352 *$ & $0.669 *$ & 0.094 & 1 & & & \\
\hline $\begin{array}{l}\text { Work condition } \\
\text { mean }\end{array}$ & $0.287^{*}$ & $0.497^{*}$ & $0.23 I^{*}$ & $0.557^{*}$ & I & & \\
\hline Safety climate & $0.552^{*}$ & $0.613 *$ & 0.096 & $0.584 *$ & $0.453 *$ & I & \\
\hline Total score & $0.598 *$ & $0.773^{*}$ & $0.428^{*}$ & $0.788 *$ & $0.739 *$ & $0.757^{*}$ & I \\
\hline
\end{tabular}

Note: $* p<0.01$ significance level. 
Table 4 Total and Subscale Scores of Medical Staff Attitudes Towards Patient Safety in PHCs

\begin{tabular}{|l|l|c|c|c|c|c|}
\hline Subscale & N & Minimum & Maximum & Mean & SD & Score \\
\hline Teamwork & 288 & 1.17 & 5.00 & 4.11 & 0.595 & 77.5 \\
Safety climate & 288 & 1.50 & 5.00 & 3.74 & 0.778 & 68.5 \\
Job satisfaction & 288 & 1.20 & 5.00 & 4.20 & 0.720 & 80 \\
Stress recognition & 288 & 1.00 & 5.00 & 3.01 & 1.130 & 50 \\
Perception of management & 288 & 1.00 & 5.00 & 3.75 & 0.859 & 68.6 \\
Work condition & 288 & 1.00 & 5.00 & 3.50 & 0.797 & 62.6 \\
Total score & 288 & 1.85 & 4.89 & 3.72 & 0.521 & 68 \\
\hline
\end{tabular}

scale of 77.5) perception of management, (3.75 with $100 \mathrm{Pt}$ scale of 68.6$)$, safety climate (3.74 with $100 \mathrm{Pt}$ scale of 68.5), work conditions ( 3.50 with $100 \mathrm{Pt}$ scale of 62.6$)$ and stress recognition (3.01 with $100 \mathrm{Pt}$ scale of 50). However, the total score was found to be 3.72 (with a $100 \mathrm{Pt}$ scale of 68). Overall, Job satisfaction and teamwork subscales among all safety attitude subscales received scored greeter than $75 \%$.

This section shows the participant's responses for each item in the six subscales of SAQ. It presents mean scores, standard deviation (SD), and frequencies of participants' agreement (slightly agree and strongly agree) and disagreement (slightly disagree and strongly disagree) with each item in the subscales Table 5 .

This section presents the comparison between participant's perception toward the six sub-scales of patient safety and their characteristics such as gender, job category, age, experience, job title, education level, CBAHI accreditation, and PHC sectors. In comparison between the sectors, the highest total score of safety attitude was recorded in Al Omran sector (70.7) followed by $\mathrm{Al}$ Mubarraz sector (67.1) and Al Hofuf sector (66.3). Moreover, it was found that CBAHI accredited PHCs had a low total safety attitude score compared to nonaccredited (67 vs 68.7 ), however, the result was nonsignificant Table 6.

\section{Discussion}

Previous studies ${ }^{16-19}$ conducted in various regions of Saudi Arabia have explored the safety attitudes of physician and/or nurses in a specific area such as ICU or emergency department as well as at the level of the hospital. According to Alahmadi, ${ }^{20}$ Saudi Arabian hospitals in cities like Riyadh are struggling to enhance their patient safety and quality of care by utilizing safety system applications as well as creating a safety culture. Moreover, Al-Khaldi ${ }^{21}$ explored the attitude of physicians at primary health-care centers in Aseer region toward patient safety.

Correlation analysis in the current study indicated that stress recognition was least positively correlated with subscales teamwork, job satisfaction, perception of management, and safety climate although the analysis was nonsignificant, which is consistent with a study ${ }^{22}$ carried out in Albanian hospitals as there was the least positive and nonsignificant correlation between stress recognition with perceptions of management, the teamwork climate, and job satisfaction. Similar findings were also found in a study ${ }^{9}$ exploring safety attitudes among the staff of a primary health-care facility in Slovenia and it was reported that stress recognition was not significantly correlated with other subscales. However, the total score for each subscale in our study was more positively correlated with perception of management, job satisfaction, safety climate, and work condition ranging from 0.739 to 0.788 . Nevertheless, the least positive correlation of total score was with stress recognition and teamwork ranging from 0.428 to 0.598 .

Subscale stress recognition had the lowest mean, which indicates that the acceptance of how work is affected by stressors is less recognized among all the subscales which is consistent with other studies. ${ }^{22,23}$ Identifying that stress from work necessities can be a cause of sickness, disturbing usual work routines, and subsequently reduced quality of care, are perceptions that need to be recognized by health-care professionals. ${ }^{23}$ There is a strong relationship between patient safety and fatigue, anxiety, as well as lack of motivation for not predictably doing the job, with the support and motivation of the team. This can affect an individual as well as the collective working of the patient care team and can also increase the likelihood of adverse events. $^{24,25}$

Furthermore, our study illustrated that after job satisfaction the highest total score was for teamwork (77.5) 
Table 5 Participant's Responses for Each Item in the Six Subscales of SAQ

\begin{tabular}{|c|c|c|c|c|c|}
\hline Subscales, Item Number, and Text & Disagree (\%) & Neutral (\%) & Agree (\%) & Missing (\%) & Mean (SD) \\
\hline I. Nurse input is well received in this center & $18(6.25)$ & $31(10.75)$ & $235(81.6)$ & $4(1.38)$ & $75.0(22.5)$ \\
\hline $\begin{array}{l}\text { 2. In this PHC center, it is difficult to speak up if } \\
\text { I perceive a problem with patient care }{ }^{\mathrm{a}}\end{array}$ & $239(83)$ & $17(5.9)$ & $27(9.4)$ & $5(1.73)$ & $74.9(24.8)$ \\
\hline $\begin{array}{l}\text { 3. Disagreements in this center are resolved } \\
\text { appropriately }\end{array}$ & $28(9.7)$ & $20(6.9)$ & $234(81.3)$ & $6(2.1)$ & $74.8(24.3)$ \\
\hline $\begin{array}{l}\text { 4. I have the support I need from other personnel to } \\
\text { care for patient }\end{array}$ & $22(7.6)$ & $2(6.9)$ & $242(84)$ & $4(1.4)$ & $77.5(23.3)$ \\
\hline $\begin{array}{l}\text { 5. It is easy for personnel here to ask questions when } \\
\text { there is something that they do not understand }\end{array}$ & $14(4.8)$ & $5(1.7)$ & $264(92)$ & $5(1.73)$ & $81.8(19.3)$ \\
\hline $\begin{array}{l}\text { 6. The physicians and nurses here work together as well } \\
\text { coordinated team }\end{array}$ & $15(5.2)$ & $21(7.3)$ & $243(84)$ & $9(3.1)$ & $81.2(20.9)$ \\
\hline 7. I would feel safe being treated here as a patient & $31(10.8)$ & $30(10.4)$ & $223(77.4)$ & $4(1.4)$ & $74.1(25.5)$ \\
\hline $\begin{array}{l}\text { 8. Medical errors are handled appropriately in this } \\
\text { center }\end{array}$ & $75(26)$ & $14(4.9)$ & $196(68)$ & $3(1.0)$ & $64.8(31.6)$ \\
\hline $\begin{array}{l}\text { 9. I know the proper channels to direct questions } \\
\text { regarding patient safety }\end{array}$ & $67(23.3)$ & $30(10.4)$ & $186(64.6)$ & $5(1.7)$ & $63.6(30.2)$ \\
\hline $\begin{array}{l}\text { 10. I received appropriate feedback about my } \\
\text { performance }\end{array}$ & $29(10.1)$ & $31(8.7)$ & $226(78.5)$ & $2(0.7)$ & $75.0(24.4)$ \\
\hline II. In this center it is difficult to discuss errors ${ }^{a}$ & $194(67.4)$ & $35(12.2)$ & $55(19.1)$ & $4(1.4)$ & $66.1(29.2)$ \\
\hline $\begin{array}{l}\text { 12. I am encouraged by my colleagues to report any } \\
\text { patient safety concerns I may have }\end{array}$ & $52(18.1)$ & $26(9.0)$ & $156(54)$ & $5(1.7)$ & $69.0(27.7)$ \\
\hline $\begin{array}{l}\text { 13. The culture in this center makes it easy to learn from } \\
\text { the errors of others }\end{array}$ & $50(17.4)$ & $40(13.9)$ & $191(66.3)$ & $7(2.4)$ & $66.5(26.4)$ \\
\hline 15. I like my job & $5(1.73)$ & $17(5.9)$ & $262(90.9)$ & $4(1.4)$ & $88.9(17.9)$ \\
\hline 16. Working here is like being part of a large family & $21(7.3)$ & $29(10.1)$ & $232(80.5)$ & $6(2.1)$ & $79.7(23.9)$ \\
\hline 17. This is a good place to work & $31(10.8)$ & $36(12.5)$ & $218(75.7)$ & $2(0.7)$ & $75.0(26.4)$ \\
\hline 18. I am proud to work in this center & $17(5.9)$ & $35(12.2)$ & $232(80.5)$ & $4(1.4)$ & $80.6(23.3)$ \\
\hline 19. Morale in this center is high & $17(4.9)$ & $50(17.4)$ & $216(75)$ & $5(1.7)$ & $76.4(22.8)$ \\
\hline $\begin{array}{l}\text { 20. When my workload becomes excessive my } \\
\text { performance is impaired }\end{array}$ & $129(44.8)$ & $37(12.8)$ & $124(43)$ & $8(2.8)$ & $48.1(32.8)$ \\
\hline 2I. I am less effective at work when fatigued & $123(42.7)$ & $35(12.2)$ & $122(42.4)$ & $4(1.4)$ & $50.2(33.2)$ \\
\hline $\begin{array}{l}\text { 22. I am more likely to make errors in tense or hostile } \\
\text { situations }\end{array}$ & $139(48.2)$ & $34(11.8)$ & $113(46.2)$ & $2(0.7)$ & 5I.I (33.9) \\
\hline $\begin{array}{l}\text { 23. Fatigue impairs my performance during emergency } \\
\text { situations }\end{array}$ & $129(44.8)$ & $51(17.7)$ & $102(35.4)$ & $6(2.1)$ & $51.2(31.9)$ \\
\hline 24. Management supports my daily efforts & $4 \mid(14.2)$ & $55(19.1)$ & $189(65.6)$ & $3(1.0)$ & $67.9(25.9)$ \\
\hline $\begin{array}{l}\text { 25. Management does not knowingly compromise } \\
\text { patient safety }\end{array}$ & $67(23.2)$ & $47(16.3)$ & $169(58.7)$ & $5(1.7)$ & $62.8(29.5)$ \\
\hline
\end{tabular}

(Continued) 
Table 5 (Continued).

\begin{tabular}{|l|c|c|c|c|c|}
\hline Subscales, Item Number, and Text & Disagree (\%) & Neutral (\%) & Agree (\%) & Missing (\%) & Mean (SD) \\
\hline 26. Management is doing a good job & $28(9.7)$ & $38(13.2)$ & $218(75.7)$ & $4(1.4)$ & $73.6(24.4)$ \\
\hline $\begin{array}{l}\text { 27. Problem personnel are dealt with constructively by } \\
\text { the center management }\end{array}$ & $35(12.1)$ & $52(18.1)$ & $194(67.4)$ & $7(2.4)$ & $70.2(26.8)$ \\
\hline $\begin{array}{l}\text { 28. I get adequate timely information about events that } \\
\text { might affect my work }\end{array}$ & $4 I(14.2)$ & $50(17.4)$ & $195(67.7)$ & $2(0.7)$ & $68.4(26.1)$ \\
\hline $\begin{array}{l}\text { 29. The levels of staffing in this center are sufficient to } \\
\text { handle the number of patients }\end{array}$ & $134(46.5)$ & $49(17)$ & $103(35.8)$ & $2(0.7)$ & $45.9(32.1)$ \\
\hline $\begin{array}{l}\text { 30. This center does a good job of training new } \\
\text { personnel }\end{array}$ & $42(14.6)$ & $33(11.5)$ & $208(72.2)$ & $5(1.7)$ & $68.8(24.3)$ \\
\hline $\begin{array}{l}\text { 3I. All the necessary information for diagnostic and } \\
\text { therapeutic decisions is routinely available to me }\end{array}$ & $36(12.5)$ & $56(19.4)$ & $188(65.3)$ & $8(2.8)$ & $68.1(23.8)$ \\
\hline $\begin{array}{l}\text { 32. Trainees in my discipline are adequately supervised in } \\
\text { this center }\end{array}$ & $32(I I . I)$ & $64(22.2)$ & $183(63.5)$ & $9(3.1)$ & $68.0(23.7)$ \\
\hline
\end{tabular}

Notes: ${ }^{a}$ Indicates that the question was reversed. SAQ subscale items adapted from Sexton JB, Helmreich RL, Neilands TB, et al. The Safety Attitudes Questionnaire: Psychometric Properties, Benchmarking Data, and Emerging Research. BMC Health Services Research. 2006;6:44. ${ }^{7}$ C 2006 Sexton et al; licensee BioMed Central Ltd. Creative Commons Attribution License (http://creativecommons.org/licenses/by/2.0).

followed by perception of management (68.6), safety climate (68.5), and work conditions (62.6). In an era of growing complexity and several specialized professionals working together in patient care process demands effective communication and teamwork to consistently produce the best patient care. ${ }^{26}$

It has been seen in the present study that the secondlowest score regarding safety attitude was recorded in subscale working conditions ie, 62.6. Furthermore, the findings of the study revealed that many fields of the work life of nurses in PHC need strategic reorganization such as attitudes of the public, family needs, management and supervision, professional development opportunities, salary factors, staffing, working atmosphere, and duty hours.

Concerning the gender of study participants, the analysis revealed that teamwork and stress recognition score was found to be significantly high among the female gender compared to the male gender. These findings are consistent with other studies that have been carried out in the PHCs of Kuwait and Egypt. ${ }^{1,4}$

The comparison between the score of participant's experiences revealed that teamwork, job satisfaction, stress recognition, perception of management, and total safety attitude score significantly high among those with less than ten years of experience compared to those with greater than ten years of experience.
Contradictory to our findings a study ${ }^{2}$ from Palestinian hospitals reported that patient safety attitudes became more positive with increasing years of experience in some subscales.

Similarly the comparison between the participant's age and their safety attitude, in the current study, it was observed that the teamwork, job satisfaction, stress recognition, perception of management, as well as total score was significantly high among those who were less than 40 years old compared to those who were more than 40 years old. The possible explanation of this result is that the participant's age could be associated with their years of experience.

The comparison between the score of physicians vs nonphysicians in the present study revealed that perception of management was significantly low among physicians. Alzahrani $^{27}$ explored physicians' and nurses' attitudes toward patient safety in the Saudi Armed Forces Hospitals in the eastern region and reported that less than half of nurses and doctors had positive attitudes toward patient safety, especially on the subscales of stress recognition and perceptions of management. It has also been reported previously that health-care workers were likely to deny the effect of stress and fatigue on their performance. ${ }^{14,28-30}$

There were some notable differences in scores among types of staff, ie managerial vs nonmanagerial staff. It was 
Table 6 Comparison Between Participant's Characteristic and Their Attitude Scores Toward Patient Safety

\begin{tabular}{|c|c|c|c|c|c|c|c|}
\hline Sub-Scales & TW & SC & JP & SR & PM & WC & Overall Score \\
\hline Mean (SD) & $77.5(15.1)$ & $68.5(19.4)$ & $80(18.0)$ & $50(28.3)$ & $68.6(21.5)$ & $62.6(19.9)$ & $68.0(13.1)$ \\
\hline \multicolumn{8}{|l|}{ Sectors of the PHC } \\
\hline Al Hofuf & $75.3(17.6)$ & $67.5(20.9)$ & $79.7(19.7)$ & $47.6(28.6)$ & $68.6(23.9)$ & $59.6(21.4)$ & $66.4(14.4)$ \\
\hline Al Mubarraz & $79.3(14.7)$ & $68.3(19.3)$ & $77.3(17.6)$ & $50.0(26.0)$ & $65.9(20.4)$ & $61.9(18.4)$ & $67.1(11.9)$ \\
\hline Al Omran & 77.9 (II.7) & $69.8(17.7)$ & $84.3(15.9)$ & $53.5(30.6)$ & $72.2(19.6)$ & $66.9(19.7)$ & $70.8(12.3)$ \\
\hline$F$ & 1.857 & 0.328 & 3.654 & 0.993 & 2.078 & 3.095 & 2.916 \\
\hline$p$-value & 0.158 & 0.721 & 0.027 & 0.372 & 0.127 & 0.047 & 0.056 \\
\hline \multicolumn{8}{|l|}{ CBAHI accreditation } \\
\hline Yes & $77.0(14.1)$ & $68.6(18.9)$ & $79.5(18.8)$ & $47.6(28.5)$ & $67.7(22.6)$ & $62.1(20.1)$ & $67.1(12.7)$ \\
\hline No & $78.1(15.8)$ & $68.4(19.9)$ & $80.6(17.4)$ & $52.5(27.9)$ & $69.3(20.5)$ & $63.1(19.8)$ & $68.7(13.4)$ \\
\hline$t$-value & 0.593 & 0.078 & 0.527 & 1.459 & 0.624 & 0.412 & 1.016 \\
\hline$p$-value & 0.553 & 0.938 & 0.599 & 0.146 & 0.533 & 0.681 & 0.310 \\
\hline \multicolumn{8}{|l|}{ Gender } \\
\hline Male & $74.7(18.5)$ & $69.1(19.6)$ & $81.6(17.4)$ & $38.9(25.8)$ & $73.2(19.3)$ & $62.0(18.6)$ & $66.6(14.0)$ \\
\hline Female & $79.4(12.1)$ & $68.1(19.0)$ & $79.2(18.4)$ & $57.5(27.5)$ & $65.7(22.3)$ & $63.0(20.7)$ & $68.8(12.3)$ \\
\hline$t$-value & 2.539 & 0.455 & 1.103 & 5.714 & 2.907 & 0.382 & 1.390 \\
\hline$p$-value & 0.012 & 0.650 & 0.271 & 0.000 & 0.004 & 0.703 & 0.166 \\
\hline \multicolumn{8}{|l|}{ Years in the PHC Center } \\
\hline Less than 3 years & $80.8(14.0)$ & $72.8(19.9)$ & $82.9(16.4)$ & $47.6(30.5)$ & $71.6(24.2)$ & $70.3(21.2)$ & $70.9(16.7)$ \\
\hline $3-10$ years & $78.8(11.3)$ & $68.1(19.8)$ & $82.3(16.5)$ & $53.1(27.3)$ & $70.6(19.5)$ & $62.3(18.9)$ & $69.2(10.7)$ \\
\hline More than 10 years & $73.3(20.7)$ & $67.2(20.4)$ & $73.9(20.5)$ & $45.5(28.8)$ & $62.8(23.1)$ & $59.5(20.5)$ & $63.7(14.5)$ \\
\hline$F$ & 4.797 & 1.243 & 6.782 & 2.158 & 4.044 & 4.080 & 6.266 \\
\hline$p$-value & 0.009 & 0.290 & 0.001 & 0.117 & 0.019 & 0.018 & 0.002 \\
\hline \multicolumn{8}{|l|}{ Age } \\
\hline Less than 30 years & $76.3(I I .8)$ & $63.1(20.4)$ & $77.3(16.9)$ & $49.4(28.1)$ & $64.3(23.6)$ & $59.6(21.1)$ & $65.0(13.1)$ \\
\hline $30-40$ years & $80.3(13.2)$ & $70.5(19.2)$ & $84.3(16.2)$ & $55.7(27.4)$ & $74.3(18.2)$ & $65.8(18.4)$ & $71.8(11.3)$ \\
\hline More than 40 years & $73.6(19.5)$ & $69.6(18.1)$ & $74.7(20.4)$ & $40.8(27.8)$ & $61.7(22.5)$ & $59.2(19.9)$ & $63.3(13.9)$ \\
\hline$F$ & 5.418 & 3.636 & 8.568 & 7.152 & 10.957 & 3.764 & 14.058 \\
\hline$p$-value & 0.005 & 0.028 & 0.000 & 0.001 & 0.000 & 0.024 & 0.000 \\
\hline \multicolumn{8}{|l|}{ Job category } \\
\hline Nurse & $79.7(11.6)$ & $68.4(18.4)$ & $80.6(16.7)$ & $57.9(27.2)$ & $67.3(22)$ & $64.5(20.2)$ & $69.7(11.8)$ \\
\hline Technologist/technician & $76.8(12.9)$ & $68.1(19.9)$ & $80.9(18.4)$ & $47.8(27.8)$ & $74.5(18.8)$ & $63.4(20.3)$ & $68.6(12.4)$ \\
\hline Physician & $79.3(14.8)$ & $74.9(16.8)$ & $80(19.8)$ & $42.5(28.2)$ & $63.4(20.9)$ & $65(21.7)$ & $67.5(13.1)$ \\
\hline Pharmacist/pharmacy tech. & $79.4(13.2)$ & $64.3(19.6)$ & $83.6(15.8)$ & $54.1(29.5)$ & 74.7 (22.7) & $58.5(18.8)$ & $69.1(11.4)$ \\
\hline Other & $68.5(24.1)$ & $63.5(22.7)$ & 73.9 (19.8) & $40.7(25.6)$ & $63.7(21.3)$ & $56.1(15)$ & $61.1(16.9)$ \\
\hline$F$ & 4.268 & 2.523 & 1.390 & 4.337 & 3.333 & 1.765 & 3.122 \\
\hline$p$-value & 0.002 & 0.041 & 0.238 & 0.002 & 0.011 & 0.136 & 0.015 \\
\hline \multicolumn{8}{|l|}{ Job title } \\
\hline Nurse in charge & $83.6(7.72)$ & 79.7 (I2.6) & 87.7 (18.2) & $59.7(22.3)$ & $78.8(32.1)$ & $81.9(17.5)$ & $78.6(12.7)$ \\
\hline Manager & $88.8(10.8)$ & $82.6(12.3)$ & $94.3(6.91)$ & $47.9(21.6)$ & $82.1(14.9)$ & $84.8(17.9)$ & $80.1(10.1)$ \\
\hline Nonsupervisory & 77.1 (I5.2) & $67.8(19.5)$ & $79.5(18.0)$ & $50.4(28.6)$ & $67.9(21.9)$ & $61.4(19.4)$ & $67.3(12.8)$ \\
\hline$F$ & 2.860 & 3.650 & 3.194 & 0.538 & 2.558 & 9.627 & 6.659 \\
\hline$p$-value & 0.059 & 0.027 & 0.042 & 0.584 & 0.079 & 0.000 & 0.001 \\
\hline
\end{tabular}

(Continued) 
Table 6 (Continued).

\begin{tabular}{|c|c|c|c|c|c|c|c|}
\hline Sub-Scales & TW & SC & JP & SR & PM & WC & Overall Score \\
\hline \multicolumn{8}{|c|}{ Education level } \\
\hline Diploma & $76.3(15.3)$ & 65.7 (19.8) & $78.9(17.6)$ & $5 I .1(27.8)$ & $67.8(21.7)$ & $61.5(19.7)$ & $66.9(13.0)$ \\
\hline Bachelor & $81.2(13.8)$ & $74.2(17.7)$ & $83.2(18.3)$ & $48.1(28.9)$ & 70.9 (20.9) & $65.5(20.7)$ & 70.5 (I3.2) \\
\hline Board & $77.6(15.0)$ & $78.8(5.4)$ & $76.4(24.4)$ & $51.8(36.9)$ & $61.9(21.5)$ & $60.7(13.8)$ & 66.8 (7.9) \\
\hline$F$ & 3.895 & 6.920 & 1.754 & 0.357 & 0.965 & 1.239 & 2.312 \\
\hline$p$-value & 0.021 & 0.001 & 0.175 & 0.700 & 0.382 & 0.291 & 0.101 \\
\hline
\end{tabular}

observed that: teamwork, safety climate, job satisfaction scores were significantly higher among managerial staff in contrast to nonmanagerial staff. This was in accordance with a study reporting managers' more positive safety attitude compared to nonmanagerial staff. ${ }^{31}$

Regarding the education level of the study participants, the analysis revealed that teamwork, safety climate and perception management was significantly high among those with a bachelor's degree education level compared to those with diploma education level. Consistent with our finding Al-Khaldi ${ }^{21}$ explored the attitude of physicians at primary health-care centers in Aseer region toward patient safety reported that those with high qualifications had a positive attitude toward patient safety.

\section{Limitations}

Due to time and resource restrictions, this research has some limitations. The sample size of the study was small to generalize the results for overall primary health-care centers operating in the Eastern Province of KSA or all of the primary health-care centers of KSA. As this study was a questionnaire-based survey it is essential to investigate more useful research approach such as hybrid methods for the safety attitude culture in PHCs.

\section{Conclusion}

With the suggestion to pay more attention to the older staff, who had a diploma education level, long working experience, and general staff position, certain improvements are needed, especially in the field of communication and stress recognition with regards to safety culture. The results could help the management of the health-care centers to introduce a systematic approach to patient safety, to tackle the weak points and improve them, to initiate a continuous assessment of safety culture, and to increase awareness of a no-blame culture.
Certain improvements are needed, especially in the field of communication and stress recognition with regard to safety culture. The results could help the management of the health-care centers to introduce a systematic approach to patient safety, to tackle the weak points and improve them, to initiate a continuous assessment of safety culture, and to increase awareness of a no-blame culture.

There is also a strong need to investigate the knowledge and skills of health-care staff to gain deep insights into the present situation. Possibly, another tool for a more comprehensive measurement of safety culture in PHCs could be utilized to recognize other factors that might be important for patient safety.

\section{Ethical Statement}

This study was approved by Imam Abdulrahman Bin Faisal University research committee with approval reference number IRB-PGS-2020-03-056. Permission was obtained from PHC managers to participate in the study after giving full information about the aim and purpose of the study. All participants signed written informed consent to confirm their willingness to participate after having the purpose of the study explained.

\section{Disclosure}

The authors report no conflicts of interest in this work.

\section{References}

1. El Shafei AMH, Zayed MA. Patient safety attitude in primary health care settings in Giza, Egypt: cross-sectional study. Int $J$ Health Plann Manage. 2019;34(2):851-861. doi:10.1002/hpm.2743

2. Alfaqawi M, Böttcher B, Abuowda Y, et al. Treating patients in a safe environment: a cross-sectional study of patient safety attitudes among doctors in the Gaza Strip, Palestine. BMC Health Serv Res. 2020;20:1-9. doi:10.1186/s12913-020-05230-5

3. Verbakel N, Langelaan M, Verheij T, Wagner C, Zwart D. Improving patient safety culture in primary care: a systematic review. $J$ Patient Saf. 2016;12:152-158. doi:10.1097/PTS.0000000000000075 
4. Ghobashi MM, El-Ragehy HAG, Ibrahim HM, Al-Doseri FA. Assessment of patient safety culture in primary health care settings in Kuwait. Epidemiol Biostatist Public Health. 2014;11(3):e9101-1e9101-9.

5. Khamaiseh A, Al-Twalbeh D, Al-Ajlouni K. Patient safety culture in Jordanian primary health care centres as perceived by nurses: a cross-sectional study. East Mediterran Health J. 2020;34(4):101-108.

6. Al-Babtain B, Aljadhey H, Mahmoud MA, Alaqeel S, Ahmed Y. Culture of safety among nurses in a tertiary teaching hospital in Saudi Arabia. Trop J Pharma Res. 2016;5(3):639-644.

7. Sexton JB, Helmreich RL, Neilands TB, et al. The Safety Attitudes Questionnaire: psychometric properties, benchmarking data, and emerging research. BMC Health Serv Res. 2006;6(1):44. doi: 10.1186/1472-6963-6-44

8. Thomas EJ, Sexton JB, Helmreich RL. Discrepant attitudes about teamwork among critical care nurses and physicians. Crit Care Med. 2003;31(3):956-959. doi:10.1097/01.CCM.0000056183.89175.76

9. Klemenc-Ketiš Z, PoplasSusič A. Safety culture at primary healthcare level: a cross-sectional study among employees with a leadership role. Sloven J Public Health. 2019;59(1):42-46. doi: $10.2478 /$ sjph-2020-0006

10. Abdelhai R, Abdelaziz B, Ghanem S. Assessing patient safety culture and factors affecting it among health care providers at Cairo University Hospitals. J Am Sci. 2018;8:23-28.

11. Najjar S, Nafouri N, Vanhaecht K, Euwema M. The relationship between patient safety culture and adverse events: a study in Palestinian hospitals. Saf Health. 2015;1(1):1-9. doi:10.1186/ s40886-015-0008-z

12. Sorra J, Khanna K, Dyer N, Mardon R, Famolaro T. Exploring relationships between patient safety culture and patients' assessments of hospital care. J Patient Saf. 2012;8(3):131-139. doi:10.1097/ PTS.0b013e318258ca46

13. DiCuccio MH. The relationship between patient safety culture and patient outcomes: a systematic review. J Patient Saf. 2015;11 (3):135-142. doi:10.1097/PTS.0000000000000058

14. Elsous A, Akbari Sari A, AlJeesh Y, Radwan M. Nursing perceptions of patient safety climate in the Gaza Strip, Palestine. Int Nurs Rev. 2017;64(3):446-454. doi:10.1111/inr.12351

15. Zakari NM. Attitude of academic ambulatory nurses toward patient safety culture in Saudi Arabia. Life Sci J. 2011;8(3):230-237.

16. Alayed AS, Lööf H, Johansson UB. Saudi Arabian ICU safety culture and nurses' attitudes. Int J Health Care Qual Assur. 2014;27 (7):581-593. doi:10.1108/IJHCQA-04-2013-0042

17. Alzahrani N, Jones R, Abdel-Latif ME. Attitudes of doctors and nurses toward patient safety within emergency departments of two Saudi Arabian hospitals. BMC Health Serv Res. 2018;18(1):736. doi:10.1186/s12913-018-3542-7
18. Ibrahim MAM, Osman OB, Ahmed WAM. Assessment of patient safety measures in governmental hospitals in Al-Baha, Saudi Arabia. AIMS Public Health. 2019;6(4):396. doi:10.3934/ publichealth.2019.4.396

19. Mahrous MS. Patient safety culture as a quality indicator for a safe health system: experience from Almadinah Almunawwarah, KSA. $J$ Taibah Univ Med Sci. 2018;13(4):377-383. doi:10.1016/j. jtumed.2018.04.002

20. Alahmadi H. Assessment of patient safety culture in Saudi Arabian hospitals. Qual Saf Health Care. 2010;19(5):e17.

21. Al-Khaldi YM. Attitude of primary care physicians toward patient safety in Aseer region, Saudi Arabia. J Family Community Med. 2013;20(3):153. doi:10.4103/2230-8229.121976

22. Gabrani JC, Knibb W, Petrela E, Hoxha A, Gabrani A. Provider perspectives on safety in primary care in Albania. J Nurs Scholars. 2016;48(6):552-560. doi:10.1111/jnu.12236

23. Souza MM, Ongaro JD, Lanes TC, Andolhe R, Kolankiewicz A, Magnago TS. Patient safety culture in the Primary Health Care. Revista Brasileira De Enfermagem. 2019;72(1):27-34. doi:10.1590/ 0034-7167-2017-0647

24. Fermo VC, Radünz V, Rosa LD, Marinho MM. Professional attitudes toward patient safety culture in a bone marrow transplant unit. Revistagaucha De Enfermagem. 2016;37(1):e55716.

25. Barbosa MH, Aleixo T, Oliveira K, Nascimento K, Felix M, Barichello E. Patient safety climate in medical and surgical units. Rev Eletr Enf. 2016;18:7.

26. Weller J, Boyd M, Cumin D. Teams, tribes and patient safety: overcoming barriers to effective teamwork in healthcare. Postgrad Med J. 2014;90(1061):149-154. doi:10.1136/postgradmedj-2012-131168

27. Alzahrani A. Clinicians' Attitudes Toward Patient Safety: A Sequential Explanatory Mixed Methods Study in Saudi Armed Forces Hospitals [(Eastern Region) (Ph.d)]. Curtin University; 2015.

28. Flin R, Yule S, McKenzie L, Paterson-Brown S, Maran N. Attitudes to teamwork and safety in the operating theatre. Surgeon. 2006;4 (3):145-151. doi:10.1016/S1479-666X(06)80084-3

29. Grant MJC, Donaldson AE, Larsen GY. The safety culture in a children's hospital. J Nurs Care Qual. 2006;21(3):223-229. doi:10.1097/00001786-200607000-00006

30. Modak I, Sexton JB, Lux TR, Helmreich RL, Thomas EJ. Measuring safety culture in the ambulatory setting: the safety attitudes questionnaire-ambulatory version. J Gen Intern Med. 2007;22(1):1-5. doi:10.1007/s11606-007-0114-7

31. Wagner LM, Capezuti E, Rice JC. Nurses' perceptions of safety culture in long-term care settings. J Nurs Scholars. 2009;41 (2):184-192. doi:10.1111/j.1547-5069.2009.01270.x
Journal of Multidisciplinary Healthcare

\section{Publish your work in this journal}

The Journal of Multidisciplinary Healthcare is an international, peerreviewed open-access journal that aims to represent and publish research in healthcare areas delivered by practitioners of different disciplines. This includes studies and reviews conducted by multidisciplinary teams as well as research which evaluates the results or conduct of such teams or healthcare processes in general. The journal covers a very wide range of areas and welcomes submissions from practitioners at all levels, from all over the world. The manuscript management system is completely online and includes a very quick and fair peer-review system. Visit http://www.dovepress.com/testimonials. php to read real quotes from published authors. 